\title{
Behavioural responses of diamondback moth Plutella xylostella (Lepidoptera: Plutellidae) to extracts derived from Melia azedarach and Azadirachta indica
}

\author{
D.S. Charleston $^{1 *}$, R. Kfir ${ }^{1}$, L.E.M. Vet $^{2}$ and M. Dicke ${ }^{2}$ \\ ${ }^{1}$ Insect Ecology, Agricultural Research Council, Plant Protection Research \\ Institute, Private Bag X134, Queenswood 0121, South Africa: ${ }^{2}$ Plant \\ Sciences, Wageningen University, PO Box 8031, 6700EH Wageningen,
} The Netherlands

\begin{abstract}
The impact of three different doses of botanical insecticide derived from the syringa tree, Melia azedarach and the neem tree, Azadirachta indica was tested on the behaviour of the diamondback moth, Plutella xylostella (Linnaeus). Both botanical insecticides had a significant impact on larval behaviour. At higher doses the extracts showed feeding deterrent activity, with larvae preferring the untreated sides of cabbage leaves and consuming less of the treated half of cabbage leaves. The botanical insecticides had less of an effect on the oviposition behaviour of P. xylostella moths. In laboratory and glasshouse trials, significantly fewer eggs were oviposited on the plants that had been treated with syringa extracts. Therefore, the syringa extracts appear to have a repellent effect. In contrast, when exposed to the neem extracts the moths did not discriminate between control plants and treated plants. Behavioural observation indicated that, despite the lower number of eggs oviposited on cabbage treated with syringa extracts, the moths chose cabbage treated with the highest dose of syringa more often than they chose control cabbage plants. Similar observations were found in cabbage plants treated with neem, moths chose the medium dose more often than they chose the control. Oviposition and feeding deterrent properties are important factors in pest control, and results from this study indicate that botanical insecticides have the potential to be incorporated into control programmes for P. xylostella in South Africa.
\end{abstract}

Keywords: Plutella xylostella, Azadirachta indica, Melia azedarach, insecticides, plant extracts, South Africa, control

\section{Introduction}

The diamondback moth, Plutella xylostella (Linnaeus) (Lepidoptera: Plutellidae), is an oligophagous species that feeds on plant species in the family Brassicaceae (Thorsteinson, 1953), which include economically important crops such as cabbage, cauliflower, broccoli, canola and Brussels sprouts. As such it is a worldwide pest, costing over

*Fax: +27 123293278

E-mail: charlestond@arc.agric.za
US\$ 1 billion to control annually (Talekar \& Shelton, 1993). In the past, control of P. xylostella relied heavily on the use of synthetic chemical insecticides, which has resulted in the development of resistance to all modern synthetic insecticides that have been used intensively for any prolonged length of time (Talekar \& Shelton, 1993). The widespread and indiscriminate use of insecticides in South Africa has resulted in resistance of $P$. xylostella to synthetic pyrethroids, organophosphates and carbamates (Sereda et al., 1997). Currently, Bacillus thuringiensis (Bt) var. aizawai and var. kurstaki products are recommended for control of $P$. xylostella in South Africa (Nel et al., 1999). However, in other parts of 
the world $P$. xylostella has already developed resistance to $B t$ products (Tabashnik, 1994). Therefore the development of alternative control methods is essential if this pest is to be managed successfully.

Plants are a virtually inexhaustible source of structurally diverse biologically active substances, and approximately 1800 plants have been reported to possess insecticidal properties (Grainge et al., 1984). The complex combination of behavioural and physiological actions contained in these plant compounds makes it difficult for insects to evolve resistance to them (Rice, 1993). Insecticides of plant origin have been in use for a long time. The plant families Asteraceae, Fabaceae, Euphorbiaceae and Meliaceae contain most of the insecticidal plant species (Morallo-Rejesus, 1986; Schmutterer, 1995). Products from the neem tree, Azadirachta indica Juss. (Meliaceae), and the closely related syringa tree, Melia azedarach L. (Meliaceae), have been found to be extremely effective against insect pests (Schmutterer, 1995), and it has been shown that $P$. xylostella was unable to evolve resistance to $A$. indica even after 40-60 generations of exposure to extracts from this tree (Völlinger, 1995).

Botanical insecticides have particular importance to developing countries as they can be made using local tools and trees. In South Africa approximately $80 \%$ of the smallscale rural farmers that have access to water are growing cabbage as a subsistence and cash crop. The neem tree is widely distributed in Asia, Africa, the Americas, Australia and the South Pacific islands (Schmutterer, 1995), but it is not found in South Africa. However, the closely related syringa tree is an invasive plant, and therefore commonly found throughout the country.

Botanical insecticides can influence the behaviour and development of the herbivorous insects that search for or use the plant for their reproduction. Host specificity in oligophagous herbivore insects is due to gravid females showing discrimination in their choice of plant on which to oviposit, and the larvae only accepting the leaves of a few closely related species of plants as food (Thorsteinson, 1953). Brassica plants contain glucosinolates, which provide chemical defence against generalist herbivore attack (Fahey et al., 2001), although specialists such as P. xylostella, Pieris spp. (Lepidoptera: Pieridae) and Phyllotreta cruciferae (Goeze) (Coleoptera: Chrysomelidae) use these glucosinolates as feeding and oviposition stimulants (Thorsteinson, 1953; Siemens \& Mitchell-Olds, 1996; Fahey et al., 2001; van Loon et al., 2002). However, when botanical insecticides are applied to brassicas, they have been shown to alter the feeding and oviposition preferences of these specialists (Dover, 1985; Tabashnik, 1985; Javer et al., 1987; HoughGoldstein \& Hahn, 1992; Schoonhoven \& Luo, 1994). In a previous study we reported that treatment of cabbage plants with a neem formulation or with aqueous leaf extracts from the syringa tree severely disrupted the life history (i.e. survival, development and fecundity) of $P$. xylostella (Charleston, 2004). In the present study we examine the impact of these botanical insecticides on the feeding and oviposition behaviour of $P$. xylostella.

\section{Materials and methods Plant extracts}

Melia azedarach (hereafter referred to as syringa) leaves were collected from Rietondale in Pretoria, South Africa $\left(28^{\circ} 15^{\prime} \mathrm{S} ; 25^{\circ} 44^{\prime} \mathrm{E}\right)$. The leaves were collected from trees at a height of about 1.5-3.5 $\mathrm{m}$ at the beginning of the spring flush in September 1999 and placed in a glasshouse $\left(30 \pm 5^{\circ} \mathrm{C}\right)$ to dry; after which they were crushed into a fine powder and stored in an airtight container until use. Three different doses of the extract were prepared by using different weights of leaf powder, $1 \mathrm{~g}$ (low), $3 \mathrm{~g}$ (medium) and $5 \mathrm{~g}$ (high). Each extract was made with $100 \mathrm{ml}$ of distilled water. The water was heated to $48^{\circ} \mathrm{C}$, and the leaf powder was added to the water and shaken for approximately $1 \mathrm{~min}$. The extract was left in a refrigerator $\left( \pm 4^{\circ} \mathrm{C}\right)$ overnight. The following morning the extract was filtered using Advantec ${ }^{(\mathbb{R}}$ filter paper no. 2. Three drops of liquid detergent were added to the final extract to act as a surfactant, without which the extract runs off the surface of the leaf.

A commercial formulation of Azadirachta indica, Neemix $4.5^{\circledR}$ (hereafter referred to as neem), was provided by Thermo Trilogy Corporation, Columbia, USA. Three different doses were prepared: $10.7 \mu \mathrm{l}$ (low), $16 \mu \mathrm{l}$ (medium) and $32 \mu \mathrm{l}$ (high) per $100 \mathrm{ml}$ of distilled water. Three drops of liquid detergent was also added to these extracts.

The control treatment consisted of $100 \mathrm{ml}$ of distilled water mixed with three drops of liquid detergent.

\section{Experimental plants and insects}

Cabbage plants, Brassica oleracea var. capitata L. (Brassicaceae), were bought as seedlings and planted in black plastic bags in a glasshouse $\left(30 \pm 5^{\circ} \mathrm{C}\right)$, within a tent-like construction made from fine netting (mesh size $<1 \mathrm{~mm}$ ) to protect the plants from insect damage. The plants were fertilized when planted, and regularly watered.

Plutella xylostella were from a laboratory culture started in 1993. The laboratory culture was maintained on canola seedlings, Brassica napus L. (Brassicaceae). Twenty-four hours prior to the experiments first instar larvae were removed from the canola and placed on cabbage.

Insect rearing and all experiments were maintained in a controlled environment $\left(24 \pm 2^{\circ} \mathrm{C}\right.$; $65 \%$ r.h., L16:D8).

\section{Larval choice}

Entire cabbage leaves of approximately the same size $( \pm 6 \mathrm{~cm}$ diameter) and the same age ( \pm five weeks after transplant) were used. One half of the leaf (using the main vein as a reference) was treated with plant extract or the control 'treatment' and one half was left untreated. The treated half was marked with a felt tip pen, dipped into the treatment and left to dry for approximately $60 \mathrm{~min}$. Seven treatments were used: three doses prepared from syringa, three doses from neem, and one control treatment. The leaf was placed into a Petri dish with a lid $(9 \mathrm{~cm}$ diameter). Ten leaves were used for each treatment. The treatments were arranged randomly on the laboratory bench. The experiment was repeated six times. One first instar larva was placed in the Petri dish, the dish was sealed with an elastic band and the position of the larva was recorded every hour, for a period of $10 \mathrm{~h}$.

Each time the larva was observed on one half of the leaf it could not be on the other half of the leaf. The data were therefore not independent and were analysed as paired comparisons (Sokal \& Rohlf, 1995). Each larva was categorized as having been observed more often on the treated or the control side of the cabbage leaf. Within treatments, a sign test was used to determine differences in the number of 
times the larva was observed on the treated or untreated side of the leaf (Sokal \& Rohlf, 1995).

\section{Assessment of leaf consumption by P. xylostella larvae}

Leaf consumption by the larvae on either side of the leaf was estimated after $72 \mathrm{~h}$. Photocopies were made of the leaves. The photocopies were scanned into the computer at $200 \mathrm{dpi}$ (dots per inch) and the damage was assessed.

Analysis of variance was used to compare the area of the leaf surface that was consumed by the larvae. This experiment was designed as a split plot design, repeated ten times. Treatments were divided between leaves using different concentrations (low, medium and high), while the two sub-plot treatments (treated and untreated) were randomly allocated to one half of the leaf. The assumptions of normality and homogeneity of variances were met. Treatment means were separated using Fisher's protected $t$-test of least significant differences (LSD) at the 5\% level (Snedecor \& Cochran, 1980)

\section{Oviposition choice}

Cage trials

Six cages $(900 \times 450 \times 450 \mathrm{~mm})$ were used in the experiment to compare the six doses of neem and syringa extracts against a control. Two cabbage plants were placed into each cage on opposite sides. One of the plants was treated with the botanical insecticide, while the other plant was treated with the control. The treatments were applied using a small hand-held spray bottle. The plants were sprayed until run-off (approximately $100 \mathrm{ml}$ per plant) and then left to dry for $60 \mathrm{~min}$ before being placed in a cage. The cages were arranged randomly on the laboratory bench.

One gram of fresh pupae $( \pm 195$ pupae) was collected from the laboratory culture and placed into a separate cage. Approximately $48 \mathrm{~h}$ after the first moths had started to emerge, 30 female $P$. xylostella moths were collected and five moths were placed in each of the six cages for $20 \mathrm{~h}$. The cabbage plants were then removed from the cage and the number of eggs oviposited on each plant was counted. The test was repeated six times. The numbers of eggs were counted separately for the top of the leaves, the bottom of the leaves, the main stem of the plant and the plastic bag that the plant was planted in. The data were analysed as paired comparisons using Wilcoxon's signed-ranks test for two groups (Sokal \& Rohlf, 1995).

\section{Glasshouse trials}

An additional experiment was set up in a glasshouse $\left(30 \pm 5^{\circ} \mathrm{C}\right)$ in order to provide $P$. xylostella moths with a larger area for flight and searching. Female moths were given the opportunity to freely choose between all treatments and control plants. Plants were placed in a randomized block design with four plants in each block and four blocks for each treatment. All seven treatments were used in the same experiment, creating a total of 112 plants. The plants were sprayed until run-off (approximately $100 \mathrm{ml}$ per plant) using a medium sized hand-held spray bottle and then left to dry for $60 \mathrm{~min}$. The plants were placed within a tent-like construction $(5 \times 4 \times 2 \mathrm{~m})$ enclosed with fine nylon netting (mesh size: $<1 \mathrm{~mm}$ ). Approximately $48 \mathrm{~h}$ after emergence 40 mated female moths were released into the tent and left for $48 \mathrm{~h}$. The number of eggs oviposited on each plant was then counted, counts being taken for the top of the leaves, the bottom of the leaves and the bag in which the cabbage was planted. The experiment was repeated six times.

Data were analysed using the statistical program GenStat (GenStat for Windows, 2000) and analysis of variance (ANOVA). The assumptions of normality and homogeneity of variances were met. Treatment means were separated using Fisher's protected LSD at the 5\% level of significance (Snedecor \& Cochran, 1980).

\section{Observation}

While the number of eggs oviposited on each plant provides an idea of the choices made by the moths, it is perhaps more accurate to observe the first choice that moths make when they are faced with alternatives. Two plants were placed into a cage $(900 \times 450 \times 450 \mathrm{~mm})$. The plants were $450 \mathrm{~mm}$ apart. Treatments were applied using a small hand-held spray bottle; one plant was sprayed with $100 \mathrm{ml}$ of the botanical insecticide and one was sprayed with $100 \mathrm{ml}$ of the control. Approximately $48 \mathrm{~h}$ after emergence a naïve mated female moth was released between the two plants and observed until she made her first choice. The plants were moved to opposite sides after every fifth observation. New plants were used after 20 observations had been made. A total of 60 female moths were observed for each treatment.

The response of moths to plants that had been damaged by $P$. xylostella larvae was also investigated. Treatments were applied using a small hand-held spray bottle. Each plant was sprayed with either $100 \mathrm{ml}$ of the treatment or $100 \mathrm{ml}$ of the control and infested with 15 third instar P. xylostella larvae for $24 \mathrm{~h}$. The larvae were then removed and the experiment was carried out as explained above.

Plutella xylostella moth choices between treated and control plants were analysed using binomial probability functions to assess a difference from a 50-50 distribution over the two treatments. Significance indicates preference for one of the two treatments (i.e. treated or control). To investigate whether there were any differences in the responses of the female moths to damaged or undamaged plants a $\mathrm{R} \times \mathrm{C}$ Chi-square test was carried out for each botanical insecticide (Sokal \& Rohlf, 1995).

\section{Results \\ Larval choice}

There were significant differences in the larval behaviour of $P$. xylostella between the control and the different doses of the extract. The larvae were observed more frequently on the untreated side of the leaf if the leaf had been treated with the botanical insecticides (Sign test: $P<0.01$ ) (fig. 1). However, for the control leaf, which had been treated with the distilled water mixed with the liquid detergent, the differences between the frequency of observations of the larvae on either the treated side or the untreated side of the leaf was not significant (Sign test: $P>0.1$ ).

\section{Leaf consumption by P. xylostella larvae}

There were no significant differences between the treatments (ANOVA: $\mathrm{F}_{0.05(6,63)}=1.58 ; P=0.167$ ). However, there were significant differences between the amount of leaf surface consumed on the treated and untreated side of the leaf $\left(\right.$ ANOVA: $\left.\mathrm{F}_{0.05(1,63)}=45.19 ; P<0.001\right)$. In all cases larvae 


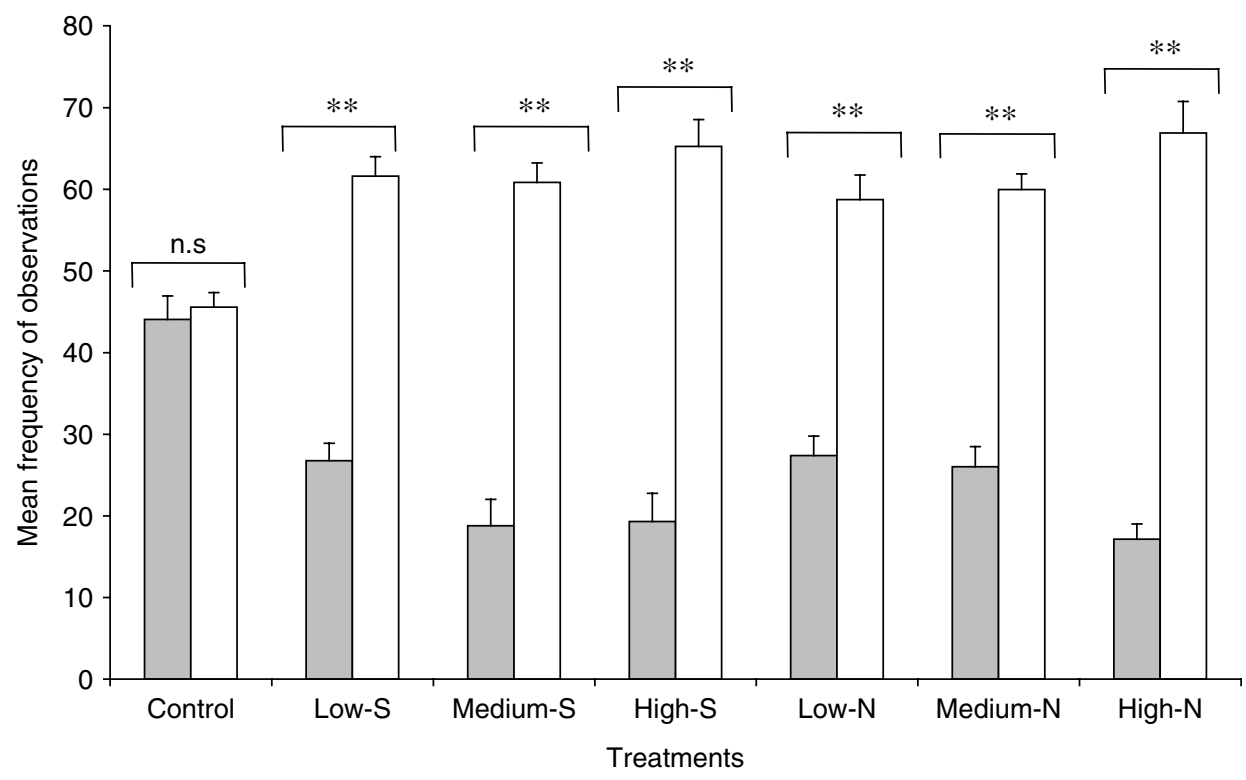

Fig. 1. Mean frequency $( \pm$ SE) that Plutella xylostella larva was observed on either the treated $(\square)$ or untreated $(\square)$ half of a cabbage leaf $(n=60)$. One half of the cabbage leaf was treated with the plant extract or the control and the other half was untreated. Low, medium and high doses of syringa $(\mathrm{S})$ or neem $(\mathrm{N})$ extract were used. For information on doses see Materials and methods. ${ }^{* *}$ Treatments with significant differences between the frequency of observations on the treated side and the untreated side of the leaf (sign test: $\alpha<0.01)$.

consumed less leaf surface on the treated side of the leaf, and these differences were statistically significant for the lowest and highest syringa treatment $(P<0.05)$ and all the doses of neem extract $(P<0.05)$ (fig. 2).
For larvae feeding on the cabbage leaf treated with the control there were no significant differences between the amount consumed on the treated and untreated sides of the leaf $(P>0.05)$ (fig. 2).

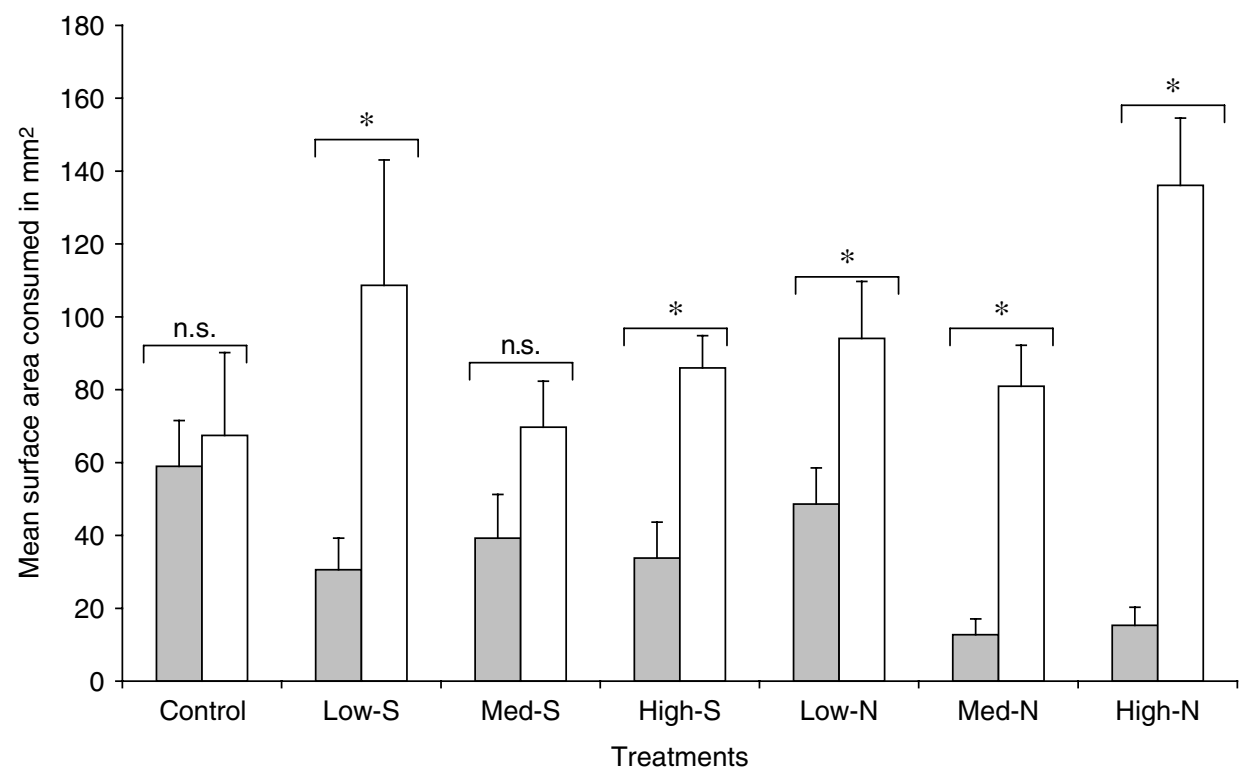

Fig. 2. Mean $( \pm \mathrm{SE})$ leaf surface area eaten by first instar Plutella xylostella during $72 \mathrm{~h}$. One half of a cabbage leaf was treated ( $\square)$ with the plant extract or the control and the other half was untreated $(\square)$. Low, medium and high doses of syringa (S) or neem (N) extract were used. For information on doses see Materials and methods. ${ }^{*}$ Treatments with significant differences between the amount eaten on the treated and untreated side of the leaf (ANOVA; plus Fisher's LSD: $\alpha=0.05$ ). 
(a)

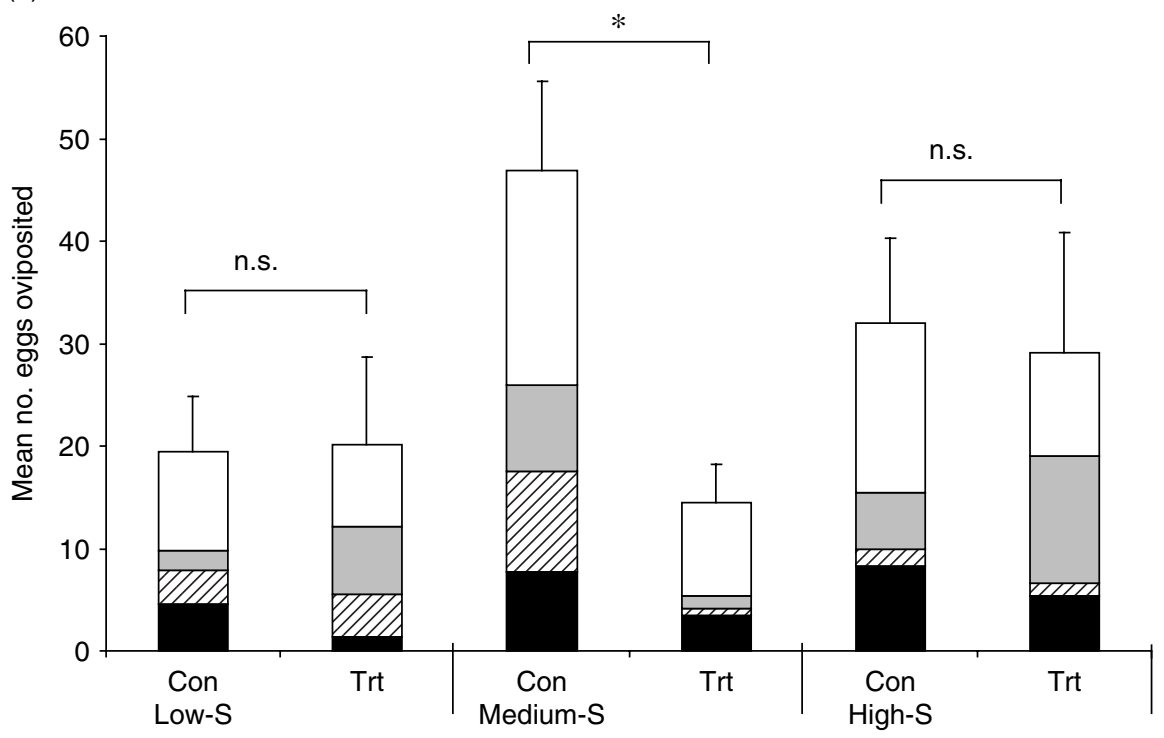

(b)

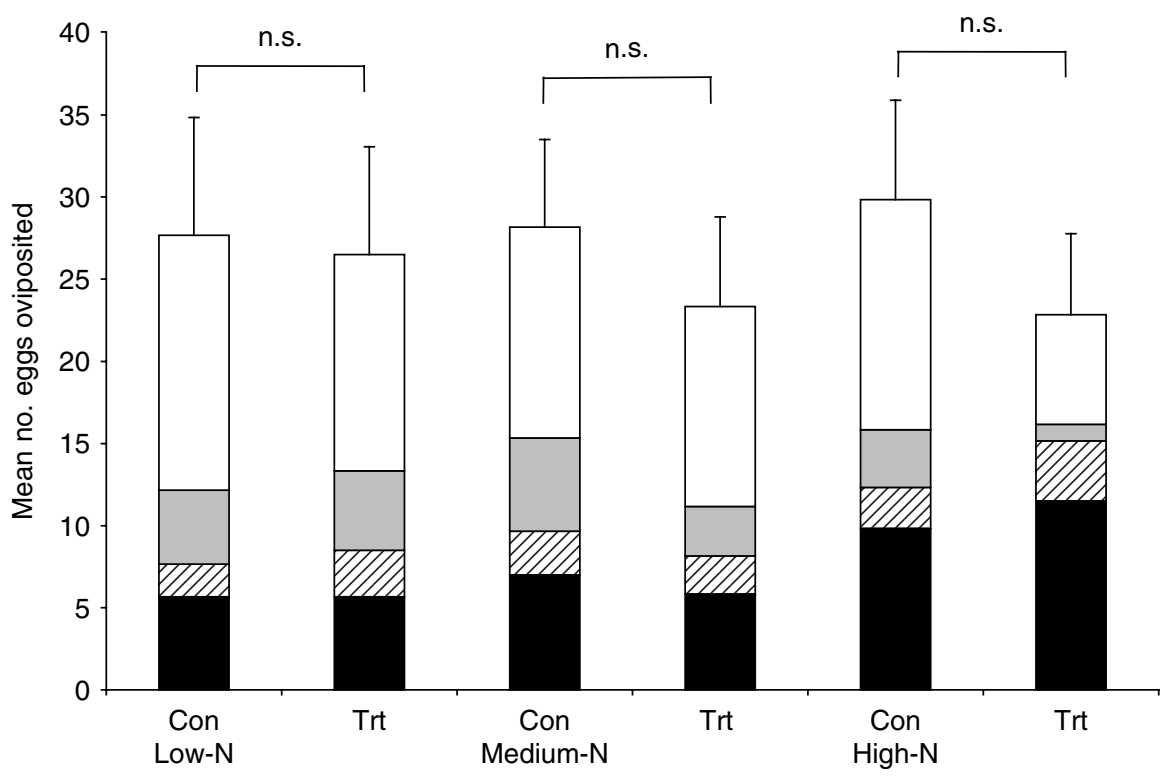

Fig. 3. Mean $( \pm$ SE) number of eggs oviposited by Plutella xylostella female moths on different parts of cabbage plants $(\square$, top surface of leaf; $\square$, bottom surface of leaf; $\square$, stem of plant; $\mathbf{\square}$, bag). Moths were given a choice between plants sprayed with the control (Con) and plants sprayed with the plant extract (Trt). The plants were treated with low, medium and high doses of (a) an aqueous leaf extract from the syringa tree $(\mathrm{s})$ or $(\mathrm{b})$ a neem solution, Neemix $4.5^{\mathbb{R}}(\mathrm{N})$. For information on doses see Materials and methods. ${ }^{*}$ Significant differences (Wilcoxon's signed-ranks: $\alpha=0.05$ ).

\section{Oviposition choice}

\section{Laboratory trials}

Syringa. The numbers of eggs oviposited on different parts of the cabbage plant or on the bag that the cabbage was planted in were counted. Most eggs were oviposited on the upper surface of the leaves (fig. 3a). The number of eggs oviposited on the bags was low, but this number increased with increasing extract concentration. The higher the concentration, the more eggs laid on the bag for both the control plant and the treated plant (fig. 3a). Comparisons were made between the cabbage plant treated with the botanical insecticide and the cabbage plant treated with the control. The only differences found were those between the control cabbage plant and the cabbage plant sprayed with the medium dose of the syringa extract, with significantly more eggs being oviposited on the control plant than on the treated cabbage plant (Wilcoxon's signed-ranks: $P=0.05$ ) 


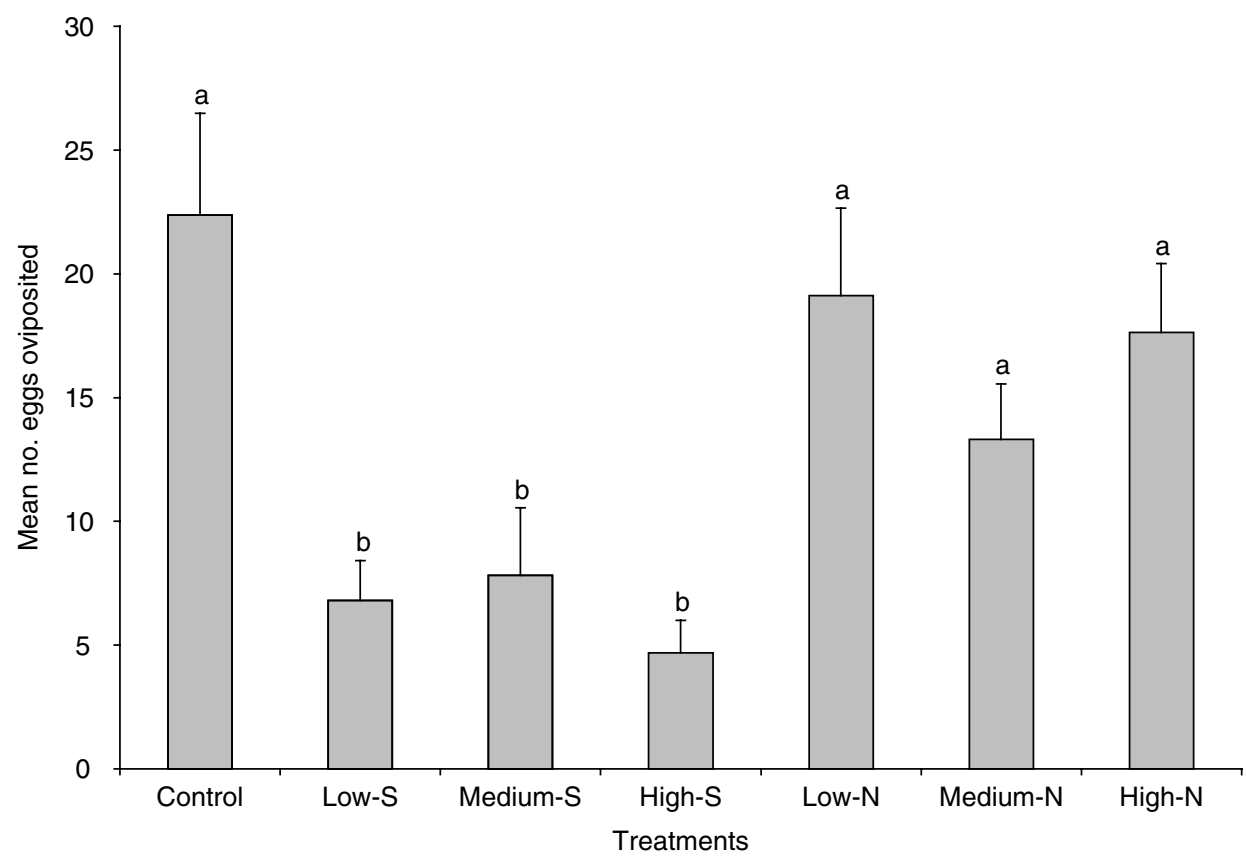

Fig. 4. Mean $( \pm$ SE) number of eggs oviposited by Plutella xylostella female moths $(n=40)$ on cabbage plants treated with low, medium and high doses of syringa $(\mathrm{s})$ or neem $(\mathrm{N})$ extracts in a glasshouse. For information on doses see Materials and methods. Bars with the same letter are not significantly different (ANOVA; plus Fisher's LSD: $\alpha=0.05$ ).

(fig. 3a). These differences were found for the number of eggs oviposited on the bottom surface of the cabbage leaves (Wilcoxon's signed ranks: $P=0.05$ ) and the stem of the cabbage plant (Wilcoxon's signed ranks: $P=0.05$ ) (fig. 3a).

Neem. Although more eggs were oviposited on the control plants than on the plants treated with the extract none of these differences were found to be significant (Wilcoxon's signed ranks: $P>0.05$ ) (fig. $3 \mathrm{~b}$ ).

\section{Glasshouse trials}

There were significant differences between the number of eggs oviposited on different treatments (ANOVA: $\left.\mathrm{F}_{0.05(6,90)}=15.18 ; P<0.001\right)$. Significantly fewer eggs were oviposited on the plants treated with the syringa extracts $(P<0.05)$ (fig. 4). There were no significant differences between the number of eggs laid on the control plant and the plants treated with the neem formulations $(P>0.05)$.

\section{Behaviour}

The choices of female $P$. xylostella moths remained the same irrespective of whether the cabbage plants were damaged by $P$. xylostella larvae or undamaged $\left(\chi^{2}\right.$ syringa: $=1.01 ; \mathrm{df}=5 ; P=0.96 ; \chi^{2}$ neem: $=4.7 ; \mathrm{df}=5$; $P=0.45$ ) (fig. 5).

On undamaged plants, the number of times that the female moths chose the treated plant first compared to the control plant was found to be significantly different for the highest dose of syringa $(P=0.029)$, and the medium dose of neem $(P=0.007)$, whereby significantly more moths preferred to fly to the treated plant than the control plant (fig. 5a). None of the other doses of the two botanical insecticides influenced the first choice of the moth.

On damaged plants significantly more moths chose the cabbage plants treated with the highest syringa concentration over the control plant $(P=0.014)$. The preference of the female moth for the medium neem treatment over the control was not found in the damaged plants (fig. 5b).

\section{Discussion}

The close association of crucifer specialists, such as $P$. xylostella, with host plants that contain glucosinolates has developed into a type of dependence on these chemicals (Renwick, 2002). The feeding responses of $P$. xylostella larvae are strongly stimulated by glucosinolates (Thorsteinson, 1953), with flavonoids further improving feeding preference, leading to the conclusion that $P$. xylostella larvae use a combination of feeding stimulants which allows for a high degree of discrimination (van Loon et al., 2002). Results from the present study show that $P$. xylostella larvae were able to detect the syringa extracts and the neem formulation. At high doses these botanical insecticides had a significant impact on the behaviour of the larvae. Larvae significantly preferred to be on the untreated side of a cabbage leaf if the leaf had been partially treated with botanical insecticides. In addition to this, significantly less leaf material was consumed on the treated side of the cabbage leaf. These botanical insecticides appear to have antifeedant properties.

Botanical insecticides derived from meliaceous plants are known to affect other crucifer specialists. Azadirachtin is the main biologically active compound found in neem-based insecticides, and electrophysiological studies have shown that azadirachtin may act on chemoreceptors (Schoonhoven, 

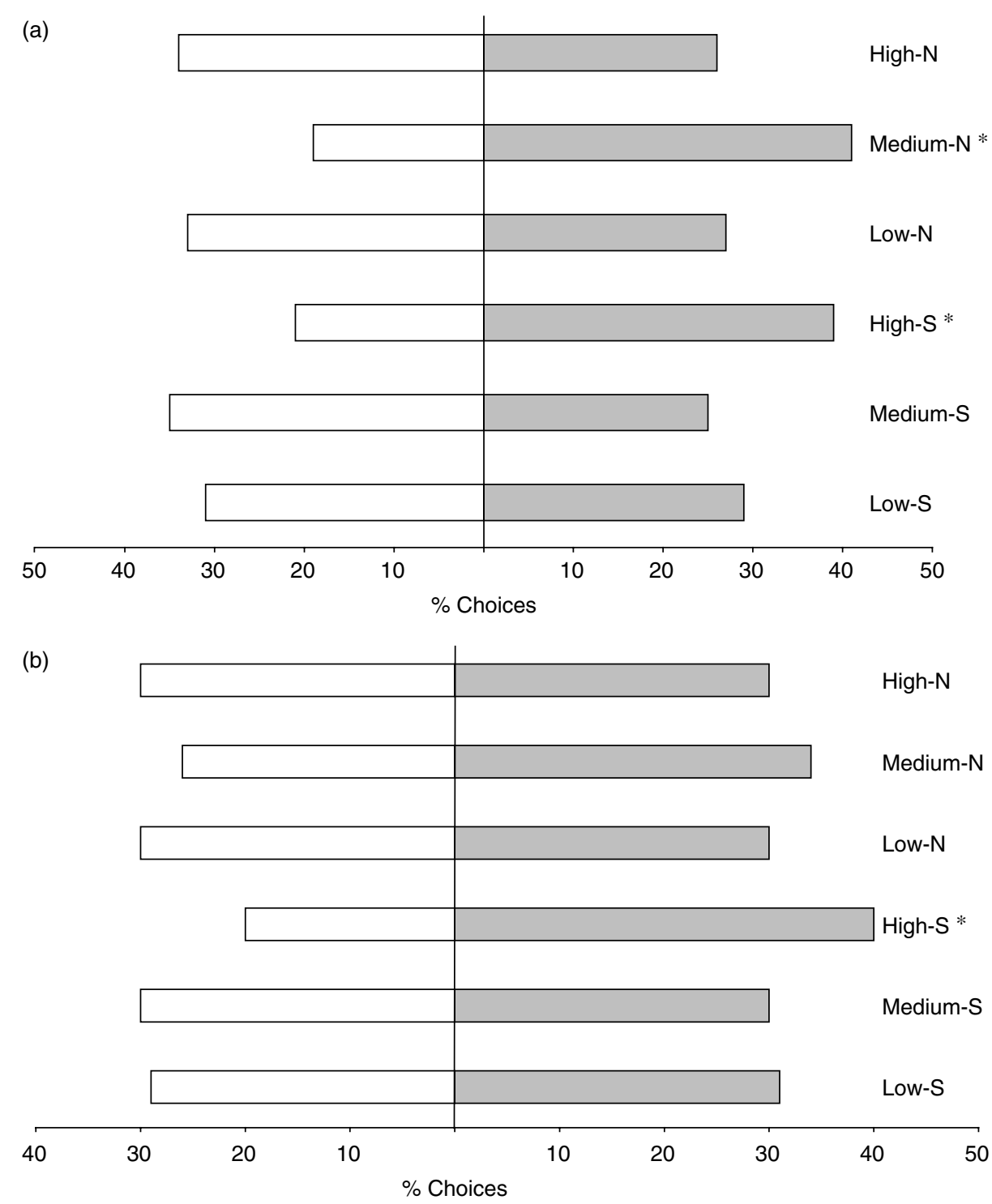

Fig. 5. First choice of Plutella xylostella moths $(n=60)$ when exposed to $(a)$ undamaged or $(b)$ damaged cabbage plants that have been treated with low, medium or high doses of syringa (S) or neem $(\mathrm{N})$ extracts $(\square$, treated; $\square$, control). For information on doses see Materials and methods. *Significantly different treatments (binomial test: $P<0.05$ ).

1982), affecting both gustatory and olfactory responses (Fagoonee, 1980). The deterrent neuron of Pieris brassicae (Linnaeus) has a very low threshold of approximately of $10^{-7} \mathrm{M}$ for azadirachtin, and this low threshold may reflect the potential bioactivity of the compound (Chapman, 2003). The triterpenoid toosendanin, a secondary compound from the tree Melia toosendan Sieb. \& Zucc. (Meliaceae), was found to have similar effects, acting as a powerful feeding deterrent to $P$. brassicae caterpillars, even at concentrations as low as $1 \mu \mathrm{M}$ (Schoonhoven \& Luo, 1994).

Host-plant finding by adult insects in crucifers may depend on the emanation of plant volatiles, and plant acceptance may depend on glucosinolates that are perceived upon contact with the plant (Renwick, 2002). For example, stimulatory and deterrent information perceived by tarsal chemoreceptors have been shown to be employed by Pieris butterflies (van Loon, 1996). Ovipositing Pieris butterflies depend on glucosinolates on the leaf surface to recognize suitable sites for their progeny to feed (Renwick et al., 1992; van Loon et al., 1992), although some crucifer genera also contain cardenolides that are potent oviposition deterrents to Pieris butterflies (van Loon \& Schoonhoven, 1999). Previous work on P. xylostella has strongly suggested that host plant recognition for oviposition by this insect is also dependent on glucosinolates (Reed et al., 1989). However, a number of plant extracts have been shown to reduce oviposition by P. xylostella, for example aqueous extracts from tansy, Tanacetum vulgare L. (Hough-Goldstein \& Hahn, 1992), alcoholic extracts of hyssop, rosemary, sage, thyme and white clover as well as essential oils from sage and thyme (Dover, 1985), 
and secondary plant compounds such as coumarin and rutin (Tabashnik, 1985). Ethanolic fruit extracts from the syringa tree have also been shown to have a deterrent effect on oviposition by P. xylostella (Chen et al., 1996). The aqueous leaf extracts from the syringa tree used in our study also acted as an oviposition deterrent to $P$. xylostella, with fewer eggs being oviposited on cabbage plants treated with the syringa extract. Results from this study suggest that the effects of oviposition stimuli in host plants are partially reduced by the syringa extract.

Neem has been demonstrated to reduce oviposition in a number of different insect species, including the dried-fruit beetle, Carpophilus hemipterus (Linnaeus) (Coleoptera: Nitidulidae), the brown plant hopper, Nilaparvata lugens (Stål) (Hemiptera: Delphacidae), and the melon fly, Dacus curcurbitae Coquillett (Diptera: Tephritidae) (Jacobsen et al., 1978; Saxena et al., 1981; Singh \& Srivastava, 1983). However, the oviposition response of $P$. xylostella to crucifers treated with neem extracts and formulations has been mixed. Chandramohan \& Nanjan (1992) found that a neem oil product reduced oviposition, but Klemm \& Schmutterer (1993) found a clear oviposition preference by P. xylostella for neem-treated cabbage. In yet another trial the number of eggs oviposited by $P$. xylostella on cabbage leaves treated with three different neem-based insecticides was not significantly different from the number of eggs oviposited on cabbages treated with water (Liang et al., 2003). The present study supports the results from Liang et al. (2003), since $P$. xylostella did not show major differential oviposition on cabbage plants treated with neem compared to control cabbage plants.

The spread of insect pests is strongly influenced by the female's choice of plant parts for oviposition and other oviposition characteristics. Therefore oviposition deterrence may be of importance to insect pest management by protecting plants from insects before any feeding damage occurs. However, if females still oviposit on low quality plants, then reduced feeding by larval stages reduces damage, which also has positive implications for pest management programmes. The neem formulation used in this study did reduce feeding by $P$. xylostella larvae, but it did not have a strong effect on oviposition. Neem products are not registered for use in South Africa, and the tree is not found in the country, therefore possibilities of using this botanical insecticide in South Africa are limited. However, results from this study indicate that aqueous leaf extracts from the syringa tree also have significant impacts on the behavioural responses of $P$. xylostella. Oviposition appears to be deterred, with females ovipositing fewer eggs on plants that had been treated with syringa extracts, and in addition larval feeding is also reduced. Therefore, the syringa extracts used in this study may provide the small-scale rural farmers in South Africa with an alternative pest control strategy.

\section{Acknowledgements}

This research was carried out through a grant awarded to the first author under the IFS/KNAW Carolina MacGillavry PhD Fellowship programme. Staff of the ARC-PPRI insectary provided the insects used in the experiments. Liesl Morey and Edith van Den Berg from the ARC-Biometry unit provided valuable statistical advice.

\section{References}

Chandramohan, N. \& Nanjan, K. (1992) Effect of plant product spray on the ovipositional behaviour of the diamondback moth, Plutella xylostella (L.). Neem Newsletter 9, 8-9.

Chapman, R.F. (2003) Contact chemoreception in feeding by phytophagous insects. Annual Review of Entomology 48, $455-484$.

Charleston, D.S. (2004) Integrating biological control and botanical pesticides for management of Plutella xylostella. PhD thesis, Wageningen University, The Netherlands.

Chen, C.-C., Chang, S.-J., Cheng, L.-L. \& Hou, R.F. (1996) Deterrent effect of the chinaberry extract on oviposition of the diamondback moth, Plutella xylostella (L.) (Lep., Yponomeutidae). Journal of Applied Entomology 120, 165-169.

Dover, J.W. (1985) The responses of some Lepidoptera to labiate herb and white clover extracts. Entomologia Experimentalis et Applicata 39, 177-182.

Fagoonee, I. (1980) The life cycle, bionomics and control of the cabbage webworm Crocidolomia binotalis Zell. (Lepidoptera, Pyralidae). Revue Agricole et Sucriere de l'Ile Maurice 59, $57-62$.

Fahey, J.W., Zalcmann, A.T. \& Talalay, P. (2001) The chemical diversity and distribution of glucosinolates and isothiocyanates among plants. Phytochemistry 56, 5-51.

GenStat for windows (2000) Release 4.2. 5th edn. VSN International Ltd, Oxford.

Grainge, M., Ahmed, S., Mitchell, W.C. \& Hylin, J.W. (1984) Plant species reportedly possessing pest-control properties - a database. Resource Systems Institute, East-West Centre, Honolulu, Hawaii.

Hough-Goldstein, J. \& Hahn, S.P. (1992) Antifeedant and oviposition deterrent activity of an aqueous extract of Tanacetum vulgare L. on two cabbage pests. Environmental Entomology 21, 837-844.

Jacobson, M., Reed, D.K., Crystal, M.M., Morneo, D.S. \& Soderstrom, E.L. (1978) Chemistry and biological activity of insect feeding deterrents from certain weeds and crop plants. Entomologia Experimentalis et Applicata 24, 448-457.

Javer, A., Wynee, A.D., Borden, J.H. \& Judd, G.J.R. (1987) Pine oil: an oviposition deterrent for the onion maggot, Delia antiqua (Meigen) (Diptera: Anthomyiidae). Canadian Entomologist 119, 605-609.

Klemm, U. \& Schmutterer, H. (1993) Effects of neem preparations on Plutella xylostella L. and its natural enemies of the genus Trichogramma. Zeitschrift für Pflanzenkrankheiten und Pflanzenschutz 100, 113-128.

Liang, G.M., Chen, W. \& Liu, T.X. (2003) Effects of three neembased insecticides on diamondback moth (Lepidoptera: Plutellidae). Crop Protection 22, 333-340.

Morallo-Rejesus, B. (1986) Botanical insecticides against the diamondback moth. pp. 241-255 in Diamondback moth management. Taiwan, 11-15 March, 1985. Asian Vegetable Research and Development Centre, Shanhua, Taiwan.

Nel, A., Krause, M., Ramautar, N. \& van Zyl, K. (1999) A guide for the control of plant pests. National Department of Agriculture, Republic of South Africa.

Reed, D.W., Pivnick, K.A. \& Underhill, E.W. (1989) Identification of chemical oviposition for the diamondback moth, Plutella xylostella, present in three species of Brassicaceae. Entomologia Experimentalis et Applicata 53, 277-286.

Renwick, J.A.A. (2002) The chemical world of crucivores: lures, treats and traps. Entomologia Experimentalis et Applicata 104, $35-42$. 
Renwick, J.A.A., Radke, C.D., Sachdev-Gupta, K. \& Städler, E. (1992) Leaf surface chemicals stimulating oviposition by Pieris rapae (Lepidoptera: Pieridae) on cabbage. Chemoecology 3, 33-38.

Rice, M. (1993) Built-in resistance prevention (BIRP): a valuable property of azadirachtin. pp. 13-14 in World Neem Conference, Bangalore, India.

Saxena, R.C., Liquido, N.J. \& Justo, H.D. (1981) Neem seed oil, a potential antifeedant for the control of the rice brown planthopper, Nilaparvata lugens. pp. 171-188 in Schmutterer, H., Ascher, K.R.S. \& Rembold, H. (Eds) Natural pesticides from the neem tree (Azadirachta indica A. Juss.). Eschborn, Germany, GTZ Press.

Schmutterer, H. (1995) The neem tree: source of unique natural products for integrated pest management, medicine, industry and other purposes. Weinheim, VCH Verlagsgesellschaft.

Schoonhoven, L.M. (1982) Biological aspects of antifeedants. Entomologia Experimentalis et Applicata 31, 57-69.

Schoonhoven, L.M. \& Luo, L.-E. (1994) Multiple mode of action of the feeding deterrent, toosendanin, on the sense of taste in Pieris brassicae larvae. Journal of Comparative Physiology A 175, 519-524.

Sereda, B., Basson, N.C.J. \& Marais, P. (1997) Bioassay of insecticide resistance in Plutella xylostella (L.) in South Africa. African Plant Protection 3, 67-72.

Siemens, D.H. \& Mitchell-Olds, T. (1996) Glucosinolates and herbivory by specialists (Coleoptera: Chrysomelidae, Lepidoptera: Plutellidae): consequences of concentration and induced resistance. Environmental Entomology 52, 1344-1353.

Singh, R.P. \& Srivastava, B.G. (1983) Alcohol extract of neem (Azadirachta indica A. Juss) seed oil as oviposition deterrent for Dacus cucurbitae (Coq.). Indian Journal of Entomology 45, 497-498.

Snedecor, G.W \& Cochran, W.G. (1980) Statistical methods. 7th edn. Iowa, Iowa State University Press.

Sokal, R.R. \& Rohlf, F.J. (1995) Biometry: the principles and practice of statistics in biological research. 3rd edn. New York, W.H. Freeman and Company.

Tabashnik, B.E. (1985) Deterrence of diamondback moth (Lepidoptera: Plutellidae) oviposition by plant compounds. Environmental Entomology 14, 575-578.
Tabashnik, B.E. (1994) Evolution of resistance to Bacillus thuringiensis. Annual Review of Entomology 39, 47-79.

Talekar, N.S. \& Shelton, A.M. (1993) Biology, ecology, and management of the diamondback moth. Annual Review of Entomology 38, 275-301.

Thorsteinson, A.J. (1953) The chemotactic responses that determine host specificity in an oligophagous insect (Plutella maculipennis (Curt.) Lepidoptera). Canadian Journal of Zoology 31, 52-72.

van Loon, J.J.A. (1996) Chemosensory basis of feeding and oviposition behaviour in herbivorous insects: a glance at the periphery. Entomologia Experimentalis et Applicata 80, $7-13$.

van Loon, J.J.A. \& Schoonhoven, L.M. (1999) Specialist deterrent chemoreceptors enable Pieris caterpillars to discriminate between chemically different deterrents. Entomologia Experimentalis et Applicata 91, 29-35.

van Loon, J.J.A., Blaakmeer, A., Griepink, F.C., van Beek, T.A., Schoonhoven, L.M. \& de Groot, A. (1992) Leaf surface compounds from Brassica oleracea (Cruciferae) induces oviposition by Pieris brassicae (Lepidoptera: Pieridae). Chemoecology 3, 39-44.

van Loon, J.J.A., Wang, C., Nielsen, J.K., Gols, R. \& Qiu, Y. (2002) Flavonoids from cabbage are feeding stimulants for diamondback moth larvae additional to glucosinolates: chemoreception and behaviour. Entomologia Experimentalis et Applicata 104, 27-34.

Völlinger, M. (1995) Studies of the probability of development of resistance of Plutella xylostella to neem products, pp. 477-483 in Schmutterer, H. (Ed.) The neem tree: source of unique natural products for integrated pest management, medicine, industry and other purposes. Weinheim, $\mathrm{VCH}$ Verlagegesellschaft. 


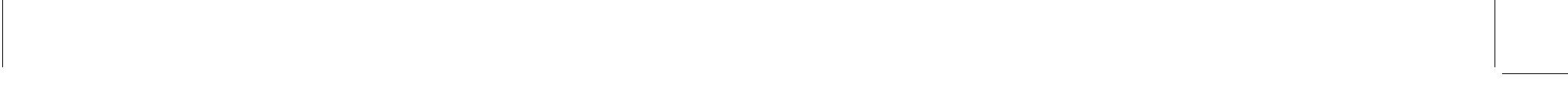

